\title{
Occurrence of the rice root nematode Hirschmanniella oryzae on monsoon rice in Myanmar
}

\author{
Zin Thu Zar Maung1,3, Pyone Pyone Kyi ${ }^{1}$, Yi Yi Myint², Thein Lwin ${ }^{2}$ \& Dirk de Waele ${ }^{3}$ \\ ${ }^{1}$ Plant Protection Division, Myanma Agriculture Service, West Gyogone, 11011 Insein, Yangon, Myanmar; ${ }^{2}$ Department of \\ Plant Pathology, Yezin Agricultural University, Yezin, Myanmar; ${ }^{3}$ Laboratory of Tropical Crop Improvement, Department of \\ Biosystems, Faculty of Bioscience Engineering, Catholic University of Leuven, 3001 Leuven, Belgium
}

Author for correspondence: Zin Thu Zar Maung, e-mail: z.t.maung@coolpets.net

\begin{abstract}
During May-October 2007, soil and root samples from 539 fields were collected from 11 monsoon rice varieties in 12 regions in Myanmar. All regions surveyed and $90 \%$ of fields sampled were infested with the rice root nematode Hirschmanniella oryzae. The average H. oryzae population was $10 / 100 \mathrm{~mL}$ soil and $419 / 20 \mathrm{~g}$ roots respectively. In $6.9 \%$ of the fields sampled $50 \mathrm{H}$. oryzae/g root were found. The average root population densities were the highest (640/20 g roots) in Taungpyan variety and the lowest (155/20 g roots) in Immayebaw variety. The lowest soil and the second-lowest root populations of $H$. oryzae were observed in Shwethweyin which may indicate that this rice variety is less susceptible to $H$. oryzae. Among three cropping sequences, the highest frequency of occurrence ( $94 \%$ ) was found in the rice-rice cropping sequence. Based on the prominence value (a combination of the frequency of occurrence and abundance) of $H$. oryzae, Hlaingtharyar was the most infested region where susceptible rice varieties are grown and rice-rice cropping sequence is practiced. The rice production in this region may be the most at risk of suffering important yield losses due to H. oryzae.
\end{abstract}

Keywords: Oryza spp., abundance, frequency of occurrence, prominence value, varietal susceptibility, varieties.

\section{INTRODUCTION}

In Myanmar, rice is the major agricultural crop and is grown throughout the country under different agroecosystems. It is grown both under rainfed lowland (monsoon) and upland conditions during the rainy season (from mid-May to mid-October) as well as under irrigated conditions during the dry summer (from midJanuary to mid-May). The total annual rice growing area is 6.4 million ha or $60 \%$ of the total cultivated land area. Monsoon rice and irrigated summer rice (paddy rice) are grown on 4 and 2 million ha, respectively, mainly in the lowlands (Nwe, 2006). Rainfed upland rice is cultivated on about 400,000 ha, mainly in the mountainous northern regions of the country. During the past decades, cultivation of two and even three rice crops per year, and the development and adoption of improved rice varieties have significantly contributed to the increase of rice production (Nwe, 2006). As a result, rice yield in Myanmar increased almost three-fold, from 8 million tons in the 1960's to about 22.4 million tons annually in $2003-2005$ or $14 \%$ of the total paddy rice production in Southeast Asia (FAO, 2006). Intensification of the rice production has also led to an increase in disease and pest problems. In Myanmar, rice is mainly grown by smallscale farmers. The crop is not only important for the food security of the majority of the population but also as a source of cash income for smallholders who sell their harvest on the local markets and in the urban areas.

There are many constraints, both abiotic and biotic, that can reduce rice yield and seed quality. Among the biotic constraints are plant-parasitic nematodes (Bridge et al., 2005). In Myanmar, Aphelenchoides besseyi, Ditylenchus angustus,Hirschmanniellaoryzae, Meloidogynegraminicola and several species of other genera such as Pratylenchus, Hoplolaimus, Criconemoides and Tylenchorhynchus, have been reported from rice (Swe, 1997; Than, 2003). Although no detailed information is at present available on the damage and yield loss plant-parasitic nematodes are causing to rice plants and rice production in Myanmar, preliminary observations have shown that several of these nematode species can cause reduction in rice yield and seed quality (Swe, 1997).

Worldwide, $H$. oryzae is the most common plantparasitic nematode on irrigated rice especially in areas with a long history of irrigated rice cultivation and when the plants are constantly flooded (Bridge et al., 2005). This nematode is perfectly adapted to the constant flooded conditions in which irrigated rice is often being grown in the lowlands (Fortuner \& Merny, 1979). It is one of the few plant-parasitic nematode species that can survive under anaerobic conditions (Babatola, 1981). In addition to Myanmar where there are indications that $H$. oryzae is widely spread in some rice producing areas, $H$. oryzae has 
also been reported on rice in other Asian countries such as India, Pakistan, Bangladesh, Sri Lanka, Nepal, Thailand, Vietnam, Indonesia, the Philippines, China, Korea and Japan (Bridge et al., 2005). In microplots, H. oryzae caused a rice yield loss of $42 \%$ when fertilizers were not applied (Fortuner, 1974) and 23\% when fertilization was adequate (Fortuner, 1977). Yield reductions ranging from 27 to 39\% were observed when rice seedlings were inoculated with inoculum levels of 1,200 nematodes/plant (Yamsonrat, 1967), 100 nematodes/plant (Mathur and Prasad, 1972) and 1-10 nematodes/g of soil (Jonathan \& Velayuthan, 1987). Babatola and Bridge (1979) even observed a decrease in grain yield with $69 \%$ of rice plants inoculated with 1,000 H. oryzae. The number of panicles (Yamsonrat, 1967) and grain weight (Mathur and Prasad, 1972; Jonathan \& Velayuthan, 1987) were affected. In Myanmar, preliminary observations showed that it can spread from infested rice nurseries to uninfested fields, and that it can cause root damage and decrease rice yield and seed quality (Than, 2003). There are also indications that $H$. oryzae is more pathogenic on the recently introduced highyielding varieties compared with the traditionally grown cultivars (Thein, 2003).

The objective of the present study was to study the frequency of occurrence and abundance of $H$. oryzae in the most important monsoon rice producing areas of Myanmar in order to estimate the potential risk this nematode species may pose for monsoon rice production in the country.

\section{MATERIALS AND METHODS}

\section{Site and plant selection}

Because in Myanmar summer rice and other crops, especially pulses, are often grown in rotation with monsoon rice, the crop history of the fields sampled was also recorded. The survey was carried out during the 2007 monsoon rice growing season (May-October) in 12 regions of the Bago, Ayeyarwaddy and Yangon Divisions in Lower Myanmar and the Mandalay Division in Upper Myanmar. In each region, on average 45 rice fields were visited, and soil and roots were collected from one commonly grown local rice variety and the rice varieties Manawthukha and Sinthwelatt. All plants sampled had been transplanted 30-45 days before the sampling and were in the tillering growth stage.

\section{Sampling}

In each rice field, a survey area of $20 \times 20 \mathrm{~m}$ was marked off by plastic ropes and within this area soil and root samples were collected from 16 plants evenly distributed over the survey area. Each selected plant was uprooted and rhizosphere soil collected up to a depth of $15 \mathrm{~cm}$. The roots were roughly washed in the field to remove the soil from the root zone. Next, the plant shoots were cut off. The soil and root samples were placed in plastic bags and transported to the laboratory where they were kept at room temperature for one night, until extraction.

\section{Estimation of Hirschmanniella oryzae population densities}

In the laboratory, the soil samples from each rice field were pooled and the nematodes were extracted from a $100 \mathrm{~mL}$ sub-sample using Whitehead's tray method (Whitehead \& Hemming, 1965). The root samples were washed again, pooled, chopped into approximately $1-\mathrm{cm}-$ pieces and thoroughly mixed. A $20 \mathrm{~g}$ sub-sample was taken from each pooled sample, triturated in a kitchen blender for $15 \mathrm{~s}$ and the nematodes were extracted from the resulting homogenate using a modified Baermann funnel method (Prot et al., 1993). After 14-16 h, the nematodes which had moved through the sieve into the water were collected and concentrated in a $10 \mathrm{~mL}$ suspension. The same day, the suspensions were examined under a stereoscopic microscope and the juvenile and adult $H$. oryzae were counted. To estimate the susceptibility and resistance of the varieties surveyed, the prominence value $(\mathrm{PV}=$ nematode population density $\mathrm{x} \sqrt{ }($ frequency of occurrence/10)) of $H$. oryzae was calculated for each rice variety and for each region (De Waele et al., 1998).

\section{RESULTS}

In total, 539 soil and root samples were collected from 11 monsoon rice varieties (Table 1). The varieties Manawthukha and Sinthwelatt were cultivated in every region surveyed. The cultivation of the other varieties was restricted to one region (five varieties) or two to three regions (Immayebaw, Hmawbisan, Hmawbi 5 and Taungpyan). Rice (Oryza sativa)-blackgram (Vigna mungo) and rice-rice were the most common cropping sequences in six and five regions, respectively, and were practised in all divisions surveyed. The rice-sesame (Sesamum indicum) cropping sequence was common in only one region, Kyaukse, in Mandalay Division.

All 12 regions surveyed and $90 \%$ of the 539 monsoon rice fields sampled were infested with $H$. oryzae (Table 2 ). The lowest frequency of occurrence of $H$. oryzae $(73.3 \%)$ was found in Nattalin. In Kyauktaga, Nyaungdone and Hlegu, all fields sampled were infested with $H$. oryzae. The number of $H$. oryzae found in the soil averaged $10 / 100 \mathrm{~mL}$ soil. The lowest average nematode soil population density $(2 / 100 \mathrm{~mL}$ soil) was in Nattalin and the highest $(30 / 100$ $\mathrm{mL}$ soil) in Hlaingtharyar. The number of $H$. oryzae found in the roots averaged 419/20 g roots. The lowest average nematode root population densities (55/20 g roots) occurred in Pyay and the highest $(1,318 / 20 \mathrm{~g}$ roots) in Hlaingtharyar region. In this region, the highest $H$. oryzae soil and root population densities were also observed: 76 and 4,551 nematodes, respectively. The highest prominence value in the soil and in the roots was also found in this region, Hlaingtharyar.

The highest frequency of occurrence of $H$. oryzae was observed in the rice-rice cropping sequence (94\%) but the difference from the other two cropping sequences was 
Occurrence of the rice root nematode Hirschmanniella oryzae...

TABLE 1 - Cropping sequence and monsoon rice varieties sampled in Myanmar and their occurrence in four divisions and 12 regions

\begin{tabular}{|c|c|c|c|c|c|c|c|c|c|c|c|c|c|}
\hline \multirow[t]{2}{*}{ Division } & \multirow[t]{2}{*}{ Region } & \multirow{2}{*}{$\begin{array}{l}\text { Cropping } \\
\text { sequence }\end{array}$} & \multicolumn{11}{|c|}{ Monsoon rice varieties } \\
\hline & & & $\underset{1}{\text { HB5 }}$ & $\begin{array}{c}\text { MN } \\
\text { H }\end{array}$ & $\begin{array}{c}\text { MN } \\
P\end{array}$ & $\begin{array}{c}\text { ShT } \\
\text { Y }\end{array}$ & $\begin{array}{l}\mathbf{H} \\
\mathbf{K}\end{array}$ & $\begin{array}{c}\text { MT } \\
\text { K }\end{array}$ & $\begin{array}{c}\text { ST } \\
\text { L }\end{array}$ & $\begin{array}{l}\mathbf{T} \\
\mathbf{P}\end{array}$ & $\begin{array}{c}\text { IY } \\
\text { B }\end{array}$ & $\begin{array}{c}\text { HB } \\
\text { S }\end{array}$ & $\begin{array}{l}\mathbf{A Y} \\
\mathbf{M}\end{array}$ \\
\hline \multirow[t]{4}{*}{ Bago } & Pyay & Rice-rice & - & - & - & - & - & + & + & - & + & - & - \\
\hline & Nattalin & $\begin{array}{l}\text { Rice- } \\
\text { Blackgram }\end{array}$ & + & - & - & - & - & + & + & + & - & + & - \\
\hline & Letpadan & $\begin{array}{l}\text { Rice- } \\
\text { Blackgram }\end{array}$ & - & - & - & - & - & + & + & - & - & - & - \\
\hline & Kyauktaga & $\begin{array}{l}\text { Rice- } \\
\text { Blackgram }\end{array}$ & + & - & - & - & - & + & + & - & - & - & - \\
\hline \multirow[t]{2}{*}{ Ayeyarwaddy } & Myaungmya & Rice-rice & - & - & - & - & + & + & + & - & - & - & - \\
\hline & NYaungdone & $\begin{array}{l}\text { Rice- } \\
\text { Blackgram }\end{array}$ & + & - & - & - & - & + & + & - & - & + & - \\
\hline \multirow[t]{3}{*}{ Yangon } & Hmawbi & $\begin{array}{l}\text { Rice- } \\
\text { Blackgram }\end{array}$ & - & + & - & - & - & + & + & - & - & - & - \\
\hline & Hlegu & Rice-rice & - & - & + & - & - & + & + & - & - & - & - \\
\hline & HLaingtharya & Rice-rice & - & - & - & - & - & + & + & + & - & - & - \\
\hline \multirow[t]{3}{*}{ Mandalay } & Kyaukse & $\begin{array}{l}\text { Rice- } \\
\text { sesame }\end{array}$ & - & - & - & - & - & + & + & - & - & - & + \\
\hline & Patheingyi & $\begin{array}{l}\text { Rice- } \\
\text { Blackgram }\end{array}$ & - & - & - & + & - & + & + & - & - & - & - \\
\hline & Pyinmana & Rice-rice & - & - & - & - & - & + & + & - & + & - & - \\
\hline
\end{tabular}

${ }^{1}$ HB5: Hmawbi 5, MNH: Manawhari, MNP: Manawpyae, ShTY: Shwethweyin, HK: Hnankar, MTK: Manawthukha, STL: Sinthwelatt, TP: Taungpyan, IYB: Immayebaw, HBS: Hmawbisan, AYM: Ayarmin.

small (Table 3). The average nematode population density of the soil in the rice-rice cropping sequence was higher than the other two cropping sequences. In the root, the average population density of $H$. oryzae was the highest in the rice-sesame cropping sequence and the lowest in the rice-blackgram cropping sequence. In the rice-rice cropping sequence, the highest $H$. oryzae population density $(4,551 / 20 \mathrm{~g}$ roots $)$ was observed in the roots.

The frequency of occurrence of $H$. oryzae on the different monsoon rice varieties ranged from 100\% (Hmawbi 5, Manawhari and Manawpyae) to $80 \%$ (Hmawbisan and Ayarmin) (Table 4). The highest average nematode soil population density $(19 / 100 \mathrm{~mL}$ soil) was in the variety Manawpyae and the lowest $(4 / 100 \mathrm{~mL})$ occurred in the varieties Shwethweyin and Ayarmin. The nematode average root population densities were highest $(640 / 20 \mathrm{~g}$ roots) in the variety Taungpyan and lowest $(155 / 20 \mathrm{~g}$ roots) in the variety Immayebaw. The highest $H$. oryzae population density in the soil was observed in the varieties Manawthukha and Taungpyan (76/100 $\mathrm{mL}$ soil) while the highest root population density was observed in the variety Manawthukha (4,551/20 g roots).
Among the different monsoon rice varieties, the highest prominence value of $H$. oryzae in the rhizosphere soil was found in the variety Manawpyae and the lowest in the varieties Shwethweyin, Immayebaw and Ayarmin. In the roots, the highest prominence value, observed in the variety Taungpyan, was four times higher than the lowest prominence value found in the variety Immayebaw.

On average, $H$. oryzae population densities in the root and soil were higher in the variety Manawthuka than in the variety Sinthwetatt (Table 5). On Manawthuka, both the soil and root population densities of $H$. oryzae were the highest in the Hlaingtharyar region $(40 / 100$ $\mathrm{mL}$ soil and 2,279/20 g roots, respectively) while the lowest $H$. oryzae soil and root population densities were observed in Nattalin $(1 / 100 \mathrm{~mL}$ soil) and Kyauktaga (64/20 g roots), respectively. On Sinthwelatt, the highest $H$. oryzae soil and root population densities were both observed in the Hlaingtharyar region $(26 / 100 \mathrm{~mL}$ soil and $878 / 20$ g roots, respectively) while the lowest $H$. oryzae soil and root population densities were observed in Patheingyi (2/100 mL soil) and Pyay (43/20 g roots), respectively. 


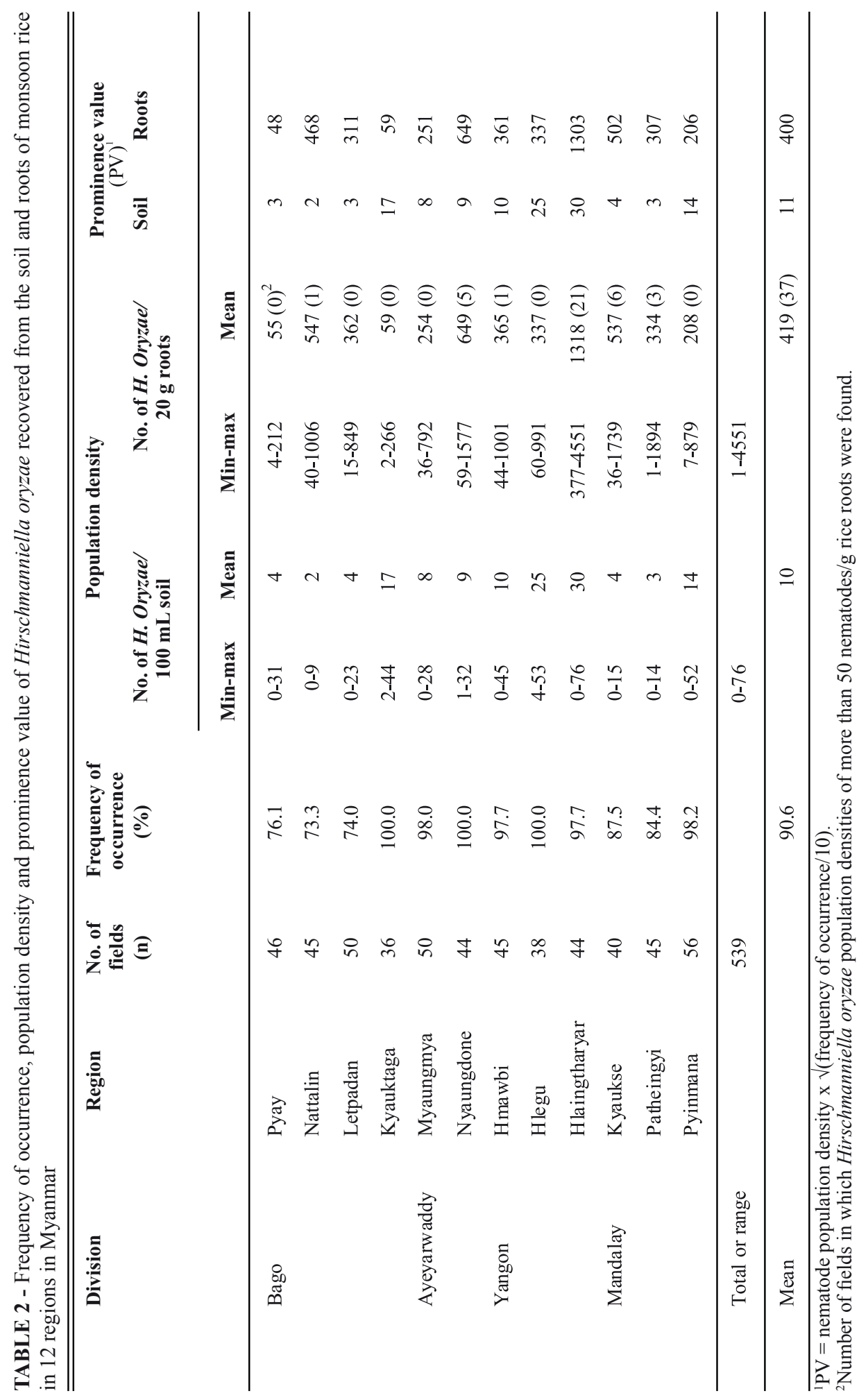


Occurrence of the rice root nematode Hirschmanniella oryzae...

TABLE 3 - Frequency of occurrence and population density of Hirschmanniella oryzae recovered from the soil and roots of monsoon rice grown in different cropping sequences

\begin{tabular}{|c|c|c|c|c|c|c|}
\hline \multirow[t]{3}{*}{ Cropping sequence } & \multirow{3}{*}{$\begin{array}{l}\text { No. of } \\
\text { fields } \\
\text { (n) }\end{array}$} & \multirow{3}{*}{$\begin{array}{c}\text { Frequency of } \\
\text { occurrence } \\
(\%)\end{array}$} & \multicolumn{4}{|c|}{ Population density } \\
\hline & & & \multicolumn{2}{|c|}{ No. of $H$. oryzae $/ 100 \mathrm{~mL}$ soil } & \multicolumn{2}{|c|}{ No. of H.oryzae/20 g roots } \\
\hline & & & $\min -\max$ & mean & $\min -\max$ & mean \\
\hline Rice-rice & 234 & 94 & $1-76$ & 16 & $4-4551$ & 434 \\
\hline $\begin{array}{l}\text { Rice-blackgram } \\
\text { (Vigna mungo) }\end{array}$ & 265 & 88 & $1-45$ & 7 & $1-1894$ & 386 \\
\hline $\begin{array}{l}\text { Rice-Sesame } \\
\text { (Sesamum indicum) }\end{array}$ & 40 & 87.5 & $1-15$ & 4 & $36-1739$ & 537 \\
\hline
\end{tabular}

TABLE 4 - Frequency of occurrence, population density and prominence value of Hirschmanniella oryzae recovered from the soil and roots of 12 monsoon rice varieties in Myanmar

\begin{tabular}{|c|c|c|c|c|c|c|c|c|}
\hline \multirow[t]{3}{*}{ Variety } & \multirow{3}{*}{$\begin{array}{l}\text { No. of fields } \\
\text { (n) }\end{array}$} & \multirow{3}{*}{$\begin{array}{c}\text { Frequency of } \\
\text { occurrence } \\
(\%)\end{array}$} & \multicolumn{4}{|c|}{ opuPation density } & \multicolumn{2}{|c|}{ PV } \\
\hline & & & \multicolumn{2}{|c|}{$\begin{array}{l}\text { No. of H.oryzae/ } \\
100 \mathrm{~mL} \text { soil }\end{array}$} & \multicolumn{2}{|c|}{$\begin{array}{c}\text { No. of H.oryzae/ } \\
20 \mathrm{~g} \text { root }\end{array}$} & \multirow[t]{2}{*}{ Soil } & \multirow[t]{2}{*}{ Roots } \\
\hline & & & Min-max & Mean & Min-max & Mean & & \\
\hline Hmawbi 5 & 20 & 100.0 & $2-32$ & 13 & $17-1577$ & 498 & 13 & 498 \\
\hline Manawhari & 15 & 100.0 & $3-29$ & 13 & $84-517$ & 285 & 13 & 285 \\
\hline Manawpyae & 15 & 100.0 & $5-41$ & 19 & $106-430$ & 256 & 19 & 256 \\
\hline Shwethweyin & 15 & 93.3 & $0-14$ & 4 & $1-1120$ & 242 & 4 & 234 \\
\hline Hnarkar & 15 & 93.3 & $0-28$ & 9 & $71-585$ & 273 & 8 & 264 \\
\hline Manawthukha & 190 & 91.5 & $0-76$ & 13 & $2-4551$ & 527 & 12 & 504 \\
\hline Sinthwelatt & 179 & 88.8 & $0-58$ & 10 & $4-1540$ & 328 & 10 & 309 \\
\hline Taungpyan & 30 & 86.6 & $0-76$ & 13 & $140-1505$ & 640 & 12 & 596 \\
\hline Immayebaw & 35 & 85.7 & $0-24$ & 5 & 5-1283 & 155 & 4 & 144 \\
\hline Hmawbisan & 10 & 80.0 & $0-13$ & 5 & $188-1008$ & 482 & 5 & 431 \\
\hline Ayarmin & 15 & 80.0 & $0-9$ & 4 & $184-1120$ & 598 & 4 & 535 \\
\hline Total or range & 539 & & $0-76$ & & $1-4551$ & & & \\
\hline Mean & & 90.8 & & 10 & & 389 & 9 & 369 \\
\hline
\end{tabular}

${ }^{1} \mathrm{PV}=$ population density $\mathrm{x} \sqrt{ }($ frequency of occurrence/10).

\section{DISCUSSION}

The frequency of occurrence of $H$. oryzae was very high: $90 \%$ of all monsoon rice fields surveyed were infested. Even in the region, Nattalin, with the lowest frequency of occurrence still about $70 \%$ of the monsoon rice fields were infested. In Asia, it is not uncommon to find such a high frequency of occurrence of $H$. oryzae in paddy rice (Ichinohe, 1988; Prot et al., 1994; Ravichandra et al., 2003). More remarkable is that during the examination of the root samples no other Hirschmanniella species and rarely other plant-parasitic nematode taxa were observed. Only in Pyay and Pyinmana regions were
Longidorus and Meloidogyne spp., respectively, sometimes also found. During similar surveys in other Asian countries usually more than one Hirschmanniella species and/or plant-parasitic nematode taxa, such as Meloidogyne spp., were found, often together with $H$. oryzae. In Japan, for instance, of about 200 paddy rice fields, $H$. oryzae occurred alone in only $10 \%$ of the fields while in $72 \%$ of the fields examined $H$. oryzae occurred together with $H$. imamuri (Ichinohe, 1988). In China, in addition to $H$. oryae 15 other Hirschmanniella species were identified in association with rice in 17 provinces where rice is being cultivated (Liao et al., 2000). 
TABLE 5 - Population densities of Hirschmanniella oryzae found in two commonly grown monsoon rice varieties in 12 regions in Myanmar

\begin{tabular}{|c|c|c|c|c|c|}
\hline \multirow[t]{2}{*}{ Division } & \multirow[t]{2}{*}{ Region } & \multicolumn{2}{|c|}{ No. of H.oryzae $/ 100 \mathrm{~mL}$ soil } & \multicolumn{2}{|c|}{ No. of H.oryzae $/ 20 \mathrm{~g}$ roots } \\
\hline & & Manawthukha & Sinthwelatt & Manawthukha & Sinthwelatt \\
\hline \multirow[t]{4}{*}{ Bago } & Pyay & 6 & 5 & 96 & 43 \\
\hline & Nattalin & 1 & 4 & 383 & 520 \\
\hline & Letpadan & 7 & 3 & 378 & 347 \\
\hline & Kyauktaga & 16 & 4 & 64 & 282 \\
\hline \multirow[t]{2}{*}{ Ayeyarwady } & Myaungmya & 11 & 7 & 346 & 171 \\
\hline & Nyaungdone & 12 & 7 & 599 & 483 \\
\hline \multirow[t]{3}{*}{ Yangon } & Hmawbi & 9 & 10 & 434 & 377 \\
\hline & Hlegu & 31 & 24 & 514 & 252 \\
\hline & Hlaingtharyar & 40 & 26 & 2279 & 878 \\
\hline \multirow[t]{3}{*}{ Mandalay } & Kyaukse & 4 & 3 & 492 & 536 \\
\hline & Patheingyi & 3 & 2 & 558 & 202 \\
\hline & Pyinmana & 15 & 18 & 282 & 205 \\
\hline Mean & & 13 & 9 & 536 & 358 \\
\hline
\end{tabular}

Based on the prominence value, a combination of the frequency of occurrence and abundance, Hlaingtharyar was the most infested region. In Hlaingtharyar, the ricerice cropping sequence is the most common rotation and the farmers use the same rice variety for the monsoon and summer rice growing season. These two factors might have contributed to the high prominence value in addition to other conditions such as a long history of rice cultivation. Bridge et al. (2005) remarked that where there is a long history of rice cultivation $H$. oryzae is likely to be widespread and abundant. In the present study, the fields sampled were established with transplanted rice plants. Sato et al. (1970) described that the adult and juvenile populations of $H$. oryzae were larger in the roots of transplanted rice. High populations of $H$. oryzae were also reported in seedlings of flooded nurseries (Miura \& Shoji, 1964; Nakazato et al., 1964). The rice varieties sampled in Hlaingtharyar were Manawthukha, Sinthwelatt and Taungpyan. All three of these varieties can be considered as good hosts of H. oryzae. In the present study, the latter variety had the highest average root population density. The soil texture of the rice fields in Hlaingtharyar is clay soil, which may be one of the factors for the detection of the highest population densities of $H$. oryzae in this region. Fortuner (1976) noted that the soil texture could explain the occurrence of $H$. oryzae. He found that the development of $H$. oryzae was better in clay soils than in sandy soils in Senegal. Mathur and Prasad (1971) also described that the highest $H$. oryzae populations were found in heavy clay soils in India.
The average soil and root population densities of $H$. oryzae in the monsoon rice fields surveyed were $10 / 100$ $\mathrm{mL}$ soil and 400/20 g roots, respectively. Sampling was done at the right time: when the plants were in the active tillering growth stage. Fortuner \& Merny (1979) stated that the maximum root population of $H$. oryzae can be found between tillering and heading stage of the rice crop. Data on the economic threshold level of $H$. oryzae on paddy rice are scarce. Grain yield was reduced about $1 / 3$ in the presence of 100 (Mathur \& Prasad, 1972) and 1000 (Babatola \& Bridge, 1979) H. oryzae per plant. In China, 15 H. oryzae/g root at the end of the maximum tillering stage was considered as an acceptable economic threshold level for the control of this nematode (Ying et al., 1996). In the present study, in $6.9 \%$ of the fields sampled $50 \mathrm{H}$. oryzae/g root were found. The majority of these fields (almost 90\%) were situated in Hlaingtharyar (56.8\%) followed by Kyaukse (16.2\%) and Nyaungdone (13.5\%). But one should keep in mind that in the present study, the population densities of $H$. oryzae were most probably underestimated because of the extraction technique used (Prot et al., 1993).

It was found that Manawthuka and Sinthwelatt were the two most commonly grown monsoon rice varieties in every region surveyed. Due to the market demand and local preference, the other varieties grown locally differ from region to region. All monsoon rice varieties sampled were susceptible to $H$. oryzae. Among the varieties included in the survey, the lowest soil and the second-lowest root populations of $H$. oryzae were observed in Shwethweyin, 
which may indicate that this rice variety is less susceptible to $H$. oryzae.

In the present survey, the variety Manawpyae had the highest population density per unit soil but a relatively low root population density compared with the other varieties, while the inverse observation was found in the variety Ayarmin. From this observation it can be assumed that a high soil nematode population density was not always correlated with a high root nematode population density.

The cropping sequence generally depends on climate, the adaptability of the crop and the economic return from the farm product. In the surveyed regions three different cropping sequences were recorded. The riceblackgram cropping sequence was the most popular among the surveyed regions. This is because of the high economic return of blackgram due to export demand. There was not much variation in the frequency of occurrence of $H$. oryzae in the three cropping sequences. Rhizosphere soil of rice plants from the rice-rice cropping sequence contained on average more nematodes per $100 \mathrm{~mL}$ soil than that from the rice-blackgram and rice-sesame cropping sequences, but this was not the case for the root population densities of $H$. oryzae. The effect of cropping sequence, was therefore not clearly found in this study. This may be due to the survival of H. oryzae. Muthukrishnan et al. (1977) and Fortuner \& Merny (1979) recounted that $H$. oryzae can survive in the soil for at least 7 months in the absence of a host plant and can stay longer than 12 months by means of quiescence in soil that is not continually wet. It can survive at high (35$\left.45^{\circ} \mathrm{C}\right)$ and low $\left(8-12^{\circ} \mathrm{C}\right)$ temperatures in fallow soil and can also survive in weeds and other hosts, in ratooning rice roots and in undecayed rice roots between crops (Mathur and Prasad, 1973; Ichinohe, 1988). In addition, Fortuner \& Merny (1979) stated that the interval between two rice crops is important for the survival of H. oryzae. In Myanmar, the duration between two rice crops is about 4 to 5 months and this may not be enough time for effective lowering of the population of $H$. oryzae in the soil.

Based on the prominence value of $H$. oryzae (a combination of the frequency of occurrence and abundance), on the susceptibility to $H$. oryzae of the rice varieties grown and on the predominant rice-rice cropping sequence, Hlaingtharyar in the Yangon Division was the most infested region and rice production in this region may be the most at risk to suffer important yield losses due to $H$. oryzae. This region is the first where yield losses of monsoon rice due to H. oryzae should be investigated.

\section{ACKNOWLEDGEMENTS}

This research was made possible thanks to a Flemish Interuniversity Council (VLIR-UOS) $\mathrm{PhD}$ scholarship to Zin Thu Zar Maung. The authors would also like to thank Mr. Myo Myint, Head of Plant Protection Division, Myanmar Agriculture Service (MAS), for his support, advice and suggestions, the staff of MAS for their technical assistance and the local farmers of the surveyed regions for their permission to take samples from their fields and their help during the survey.

\section{REFERENCES}

Babatola JO (1981) Effect of oxygen and temperature on the activity and survival of Hirschmanniella sp. Nematologica 26:289-294.

Babatola JO, Bridge J (1979) Pathogenicity of Hirschmanniella oryzae, $H$. spinicaudata and $H$. imamuri on rice. Journal of Nematology 11:128-132.

Bridge J, Plowright RA, Peng D (2005) Nematode parasites of rice. In: Luc M, Sikora RA, Bridge J (Eds.) Plant parasitic nematodes in subtropical and tropical agriculture 2nd Ed. Wallingford UK. CAB International. pp. 87-130.

De Waele D, Mcdonald AH, Jordaan EM, Orion D, Van Den Berg E, Loots GC (1998) Plant-parasitic nematodes associated with maize and pearl millet in Namibia. African Plant Protection 4:113117.

FAO (2006). FAOSTAT database. htpp://www.fao.org.

Fortuner R(1974)Evaluation des dégats causés par Hirschmanniella oryzae (Van Breda \& De Haan) Luc \& Goodey, 1963, Nématode endoparasite des racines du riz irrigué. L'Agronomie Tropicale, Nogent 29:708-714.

Fortuner R (1976) Etude écologique des nématodes des rizières du Sénégal. Cahiers de 1' ORSTOM, Série Biologique 11:179-191.

Fortuner R (1977) Fertilization du riz et dégats causés par le nématode Hirschmanniella oryzae (Van Breda \& Haan) Luc \& Goodey. Procès-verbal de la Séance du 1er Juin, 1977, Académie d'Agriculture de France 58:624-630.

Fortuner R, Merny G (1979) Root parasitic nematodes of rice. Revue de Nématologie 2:79-102.

Ichinohe M (1988) Current research on the major nematode problems in Japan. Journal of Nematology 20:184-190.

Jonathan EI, Velayutham B (1987) Evaluation of yield loss due to the rice root nematode Hirschmanniella oryzae. International Nematology Network Newsletter 4:8-9.

LiaoJL, Feng ZX, LiSM,HuYM(2000) Species of Hirschmanniella on rice and their distribution in China. Nematologia Mediterranea 28:107-110.

Mathur VK, Prasad SK (1971) Occurrence and distribution of Hirschmanniella oryzae in the Indian Union with description of H. mangaloriensis sp. Indian Journal of Nematology 1:220-226.

Mathur VK, Prasad SK (1972) Role of the rice root nematode, Hirschmanniella oryzae in rice culture. Indian Journal of Nematology 2:158-168.

Mathur VK, Prasad SK (1973) Survival and host range of the rice root nematode, Hirschmanniella oryzae. Indian Journal of Nematology 3:88-93.

Miura H, Shoji H (1964) On the distribution of the rice root nematode in Yamagata Prefecture. Annual Report Society of Plant Protection, North Japan 15:132-133.

MuthukrishnanTS, Rajendran G, RamamurthyVV, Chandrasekaran 
J (1977) Pathogenicity and control of Hirschmanniella oryzae. Indian Journal of Nematology 7:8-16.

Nakazato H, Kawashima K, Kurosawa T (1964) Seasonal occurrence of the rice root nematode. Proceedings Kanto-Tosan Plant Protection Society 11:106.

Nwe KT (2006) Rice mutation breeding for varietal improvement in Myanmar. Plant Mutation Reports 1:34.

Prot JC, Gergon EB, Matias DM (1993) Influence of extraction procedures from root samples on the recovery and infectivity of Pratylenchus zeae and Hirschmanniella oryzae. Nematologia Mediterranea 21:133-137.

Prot JC, Soriano IRS, Matias DM (1994) Major root-parasitic nematodes associated with irrigated rice in the Philippines. Fundamental and Applied Nematology 17:75-78.

Ravichandra NG, Krishnappa K, Reddy BMR (2003) Occurrence and distribution of phytoparasitic nematodes associated with rice in Mandya District, Karnataka. Indian Journal of Nematology 33:178.

Sato T, Koyama T, Koshihara T (1970) Relation between the occurrence of rice root nematodes (Hirschmanniella oryzae) Luc \& Goodey and (Hirschmanniella imamuri) Sher and the cultivation practices of paddy rice plant. Bulletin of the Tohoku National Agricultural Experiment Station 39:207-219.
Swe A (1997) Status of nematode problems and research in Myanmar. In: Sharma SB (Ed.) Diagnosis of key nematode pests of chickpea and pigeonpea and their management. Proceedings of a regional training course, Hyderabad, India, 25-30 November 1996. ICRISAT. pp. 47-52.

Than PP (2003) Survey of plant parasitic nematodes on some economic crops and study on rice root rot disease caused by Hirschmanniella oryzae (van Breda de Haan, 1902) Luc \& Goodey, 1964. M.Sc. Master Thesis. Yezin Agricultural University.

Thein K (2003) Plant protection annual report. Plant Protection Division Annual Meeting. Western Bago Division, Myanmar. [In Burmese].

Whitehead AG, Hemming JR (1965) A comparison of some quantitative methods of extracting small vermiform nematodes from soil. Annals of Applied Biology 55:25-38.

Yamsonrat S (1967) Studies on rice-root nematodes (Hirschmanniella spp.) in Thailand. Plant Disease Reporter 51:960-963.

Ying YQ, Zhou HJ, Gao XB, Feng ZX (1996) The relationship between the infection of Hirschmanniella oryzae, rice groth and yield loss. Journal of South China Agricultural University 17:1417.

TPP 9055 - Received 27 April 2009 - Accepted 15 January 2010 Section Editor: Rosangela D'Arc Lima 